\title{
Deformation-based support selection for tunnels in strainburst-prone ground
}

\author{
PK Kaiser Laurentian University, Canada
}

\begin{abstract}
Since the 1980s, many contributed to major advances in the state-of-the-art of ground control in burst-prone ground and innovative support selection procedures as well as a sophisticated tool box full of effective rock retention and support components and systems.

Most of these advances and the design of support in burst-prone ground, however, are based on the fundamental assumptions that seismic events create ground motions that damage excavations, and thus load and potentially damage the ground support. It is therefore often implied that the source of energy that causes damage stems from mining-induced seismic events. Kaiser and Cai $(2013 a, b)$ critically reviewed the support design guiding principles and identified three deficiencies with serious practical implications:

1. Standard, assumed ground motion patterns are unacceptably flawed.

2. Ground motion-related energy transfer mechanisms rarely constitute the sole source of support loading.

3. Dynamically stressed rock fails by brittle, extensional failure causing disproportional excavation convergences and support damaging deformations.
\end{abstract}

As a consequence, support needs to cope with large localised deformations and thus all support components in a support system must satisfy a deformation-based design criterion.

This paper builds on the above-mentioned articles and presents a deformation-based design concept for the control of damage caused by seismically triggered strainbursts. First, the impact of bulking deformations sustained during the failure of brittle rock masses is illustrated on the well-known ground-reaction-curve concept whereby geometric bulking deformations caused by mining-induced stress changes can be integrated. Second, it is demonstrated that the deformation demand on support is dominated by brittle failure processes in the inner shell (defined by the minor principal stress contour (at $\left.\sigma_{3} \leq U C S / 10\right)$ ). Field observations from extensometers support these findings. This is consistent with findings from discrete element modelling results presented by Garza-Cruz et al. (2014).

Next, the concept of excavation deformation potential (EDP) is introduced to assess the influence of mine stiffness on the vulnerability of an excavation to strainbursting. It is suggested that the EDP is a key parameter for the identification of potential strainburst locations. This hypothesis is then tested qualitatively on extensive strainbursting encountered during the excavation of five tunnels at the Jinping II project (China). It is concluded that potential strainburst locations correspond to locations with elevated deformation potential. From a support design perspective, it is concluded that strainburst damage can be most effectively be controlled by a support system consisting of a robust retention elements in combination with stiff rock mass reinforcements, minimising bulking, and with yielding bolts, satisfying a deformation rather than an energy demand criterion.

\section{$1 \quad$ Introduction}

Support design depends on the rock mass behaviour and the anticipated failure mode for a given excavation. As illustrated by the tunnel stability matrix in Figure 1 , the failure mode can be grouped by rock mass quality and stress level. This paper deals with conditions of massive to moderately fractured and moderately to highly stressed ground (excluding squeezing ground). Furthermore, this paper is restricted to 
brittle failing, hard rocks that exhibit both brittle extension and shear rupture (called 'spalling'; the word 'extension' is used in this paper to indicate that rupture may occur as a result tensile stresses created by extensional strain (opening cracks or fractures or extending cracks or fractures). The term spalling is typically used to describe pure tensile or extensional failure leading to slabbing. Since shear rupture is often the source of extension, the meaning of spalling is expanded to include tensile or extensional and brittle shear rupture as illustrated by Figures 2(a) and (b) (opposing arrows in (b)). Shear rupture is the primary cause for block boundary movement that, in turn, leads to extensional failure of the joint-bounded rock blocks (indicated by double arrows in Figure 2(b). These extension fractures are triggered by internal stress heterogeneities causing point loads (as in Brazilian tensile tests) due to the wavy or stepped nature of the shears.

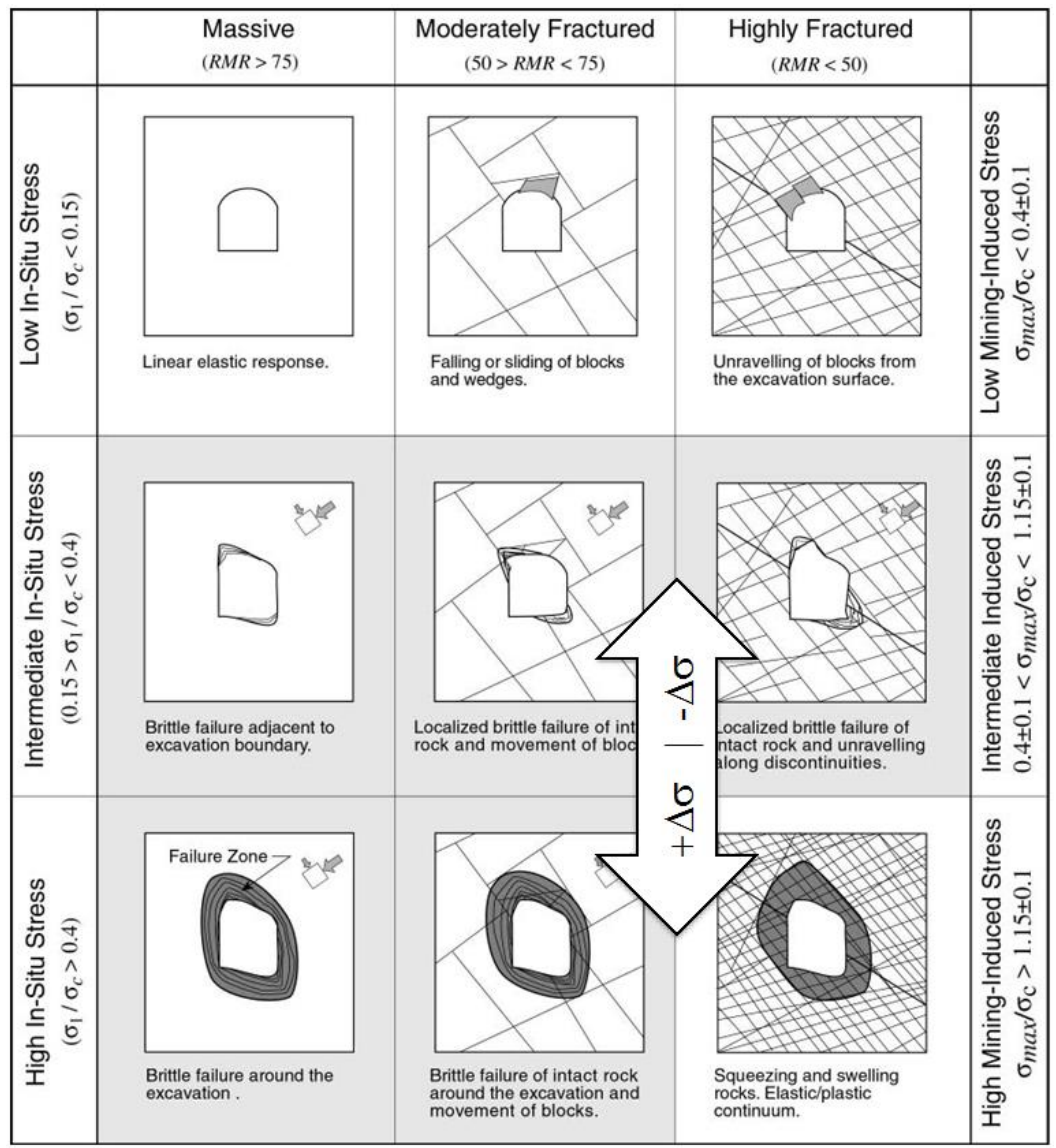

Figure 1 Tunnel behaviour matrix after Kaiser et al. (2000)

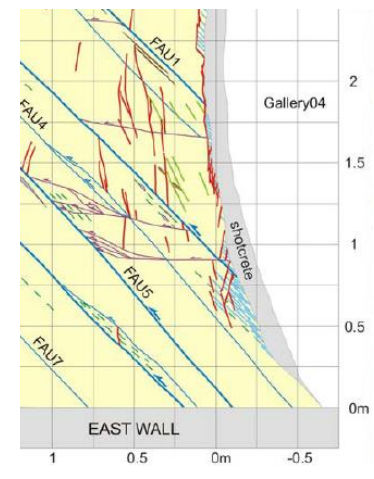

(a)

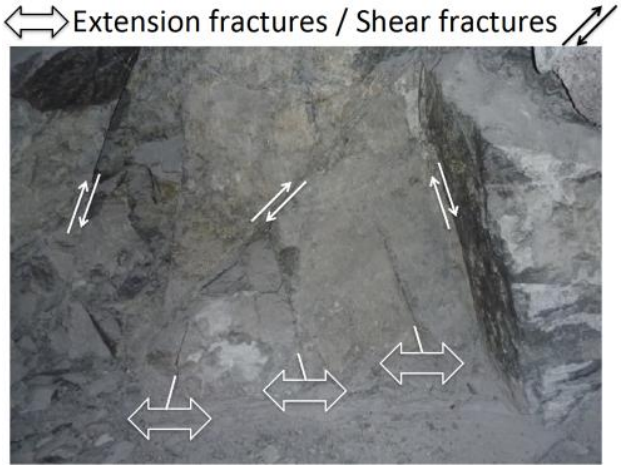

(b)

Figure 2 Examples of spalling: (a) fracturing of clay shale due to shear-induced extension fracturing (Yong et al. 2008); (b) spalling due to a combination of shear rupture along 


\section{weakness planes (rough joints) and tensile or extension fracturing of rock blocks bound by these joints (Kaiser \& Cai 2013a)}

Depending on the failure mode one or all of the following Factors of Safety (FS) need to be assessed to ensure stability of an excavation:

$$
\begin{aligned}
F S_{\text {Load }} & =\frac{\text { Support Load Capacity }}{\text { Load Demand }} \\
F S_{\text {Displacement }} & =\frac{\text { Support Displacement Capacity }}{\text { Displacement Demand }} \\
F S_{\text {Energy }} & =\frac{\text { Support Energy Capacity }}{\text { Energy Demand }}
\end{aligned}
$$

For structurally controlled failures (matrix elements 1,1 to 1,3 in Figure 1) under static conditions, the load-FS is typically assessed and is sufficient to define the safety margin. When dynamically loaded, due to a seismic event, earthquake or rockburst, a seismically induced fall of ground (Kaiser et al. 1996) may be triggered and the FS is typically assessed by adding an acceleration related component of $\mathrm{n} * \mathrm{~g}$ to the gravitational forces. Due to severe dynamic loading, a block or wedge may be ejected from the excavation wall by momentum transfer, and the $F S_{\text {Energy }}$ may be applicable. However, when an excavation is well supported, there will be no ejection of rock. A new equilibrium is established after some permanent deformation. Thus, as will be argued in this paper, it is often sufficient to satisfy the $F S_{\text {Displacement }}$ to assess the safety margin during dynamic failure. Details of support demand and capacity calculations for seismically induced falls of ground, for rock mass bulking and for rock ejection are presented in Kaiser et al. (1996).

Figure 3, based on contributions by Hoek and by Diederichs et al. (2010) and Corkum et al. (2011) provides guidance for four typical tunnelling conditions (squeezing ground (matrix 3,3 in Figure 1), structurally controlled failure (Figure 1, matrix 1,1 to 1,3), brittle failing tunnels (Figure 1, matrix 2,1 and 3,1), as well as transitional failure modes (matrix 2,$2 ; 2,3 ; 3,2)$ ) and lists typical problems, critical design parameters, applicable analytical methods, and acceptability criteria.

For the rock mass and tunnelling conditions considered in this paper, Corkum et al. (2011) suggest that both gradual and sudden (bursting) failure processes must be expected, that the applicable analysis methods are either of empirical nature or based on stress analysis using numerical models to determine the depth of failure $\left(d_{f}\right)$ and that the ultimate, probable displacements after the failure process have to be stabilised with support. As acceptability criteria, they suggest that support must be capable of stabilising fractured rock (retain broken rock) and accommodate displacements during and after the failure.

After a brief review of brittle failure processes, this paper focuses on situations where the excavations fail in a sudden, potentially violent manner, i.e. by strainbursting.

\subsection{Stress path effects}

Mining often induces significant perturbations to the virgin stress field, resulting in high deviatoric stresses $\left(\sigma_{1}-\sigma_{3}\right.$ with high or low $\left.K_{0}\right)$, stress rotations and changes in rock mass confinement $\left(\sigma_{3}\right)$. Figure 4 illustrates this using an example of measured stress changes at El Teniente Mine in Chile.

The stress path presented in Figure 4 shows that the confining pressure drops as the major principal stress increases. As a consequence, the stress deviator and thus the maximum stress ( $\sigma_{\max }=3 * \sigma_{1}-\sigma_{3}$ ) as well as the normalised stress level $\left(\sigma_{\max } / \sigma_{c}\right)$, with $\left(\sigma_{c}\right)$ as the unconfined compressive strength of the intact rock, increase. By reference to the descriptions on the right side of the tunnel behaviour matrix (Figure 1), it follows that the tunnel behaviour mode will change, as indicated by the double arrow; for this example, from a moderately stressed to a high stressed condition on one side of the excavation, and to a relaxed condition at $90^{\circ}$ from the highly stressed location. This mining-induced change in failure mode with the associated stress condition creates a potential for stress fracturing and strainbursting as well as a potential for falls of ground and seismically induced falls in the same excavation. It is interesting to note that such 
extreme stress changes may simultaneously render an excavation prone to shakedown and strainbursting. In other words, an excavation becomes vulnerable to two very different failure modes (Section 1).

\begin{tabular}{|c|c|c|c|c|c|}
\hline \multicolumn{2}{|r|}{ Tunnel condition } & Typical problems & Critical parameters & Analysis methods & Acceptability criteria \\
\hline 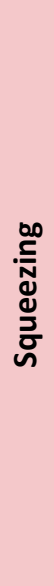 & & $\begin{array}{l}\text { Rock failure where } \\
\text { strength is exceeded by } \\
\text { induced stresses. } \\
\text { Swelling, squeezing or } \\
\text { excessive closure if } \\
\text { support is inadequate. }\end{array}$ & $\begin{array}{l}\text { - Strength of rock mass } \\
\text { and of individual } \\
\text { structural features. } \\
\text { - Swelling potential, } \\
\text { particularly with clay-rich } \\
\text { rocks. } \\
\text { - In situ stresses. } \\
\text { - Excavation method and } \\
\text { sequence. } \\
\text { - Capacity and installation } \\
\text { sequence of support } \\
\text { systems. }\end{array}$ & $\begin{array}{l}\text { Stress analysis using } \\
\text { numerical methods to } \\
\text { determine extent of } \\
\text { failure zones and } \\
\text { probable displacements } \\
\text { in the rock mass. Rock } \\
\text { support interaction } \\
\text { analysis using closed- } \\
\text { form, empirical or } \\
\text { numerical methods to } \\
\text { determine capacity and } \\
\text { installation sequence for } \\
\text { support and to estimate } \\
\text { displacements in the rock } \\
\text { mass. Tunnel strain } \\
\text { evaluation using } \\
\text { statistical-based charts. }\end{array}$ & $\begin{array}{l}\text { Capacity of installed } \\
\text { support should be } \\
\text { sufficient to stabilise the } \\
\text { rock mass and to limit } \\
\text { closure to an acceptable } \\
\text { level. Tunnelling machines } \\
\text { and internal structures } \\
\text { must be designed for } \\
\text { closure of the tunnel as a } \\
\text { result of swelling or time- } \\
\text { dependent deformation. } \\
\text { Monitoring of } \\
\text { deformations is an } \\
\text { important aspect of } \\
\text { construction control. }\end{array}$ \\
\hline 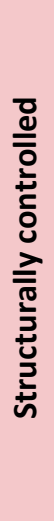 & & $\begin{array}{l}\text { Gravity driven falling or } \\
\text { sliding wedges or } \\
\text { blocks defined by } \\
\text { intersecting structural } \\
\text { features. High stresses } \\
\text { may confine wedges or } \\
\text { blocks contributing to } \\
\text { overall stability. } \\
\text { Otherwise, unravelling } \\
\text { of inadequately } \\
\text { supported surface } \\
\text { material. }\end{array}$ & $\begin{array}{l}\text { - Orientation, inclination } \\
\text { and shear strength of } \\
\text { structural features. } \\
\text { - Shape and orientation of } \\
\text { tunnel. } \\
\text { - Quality of excavation } \\
\text { drilling and blasting. } \\
\text { - In situ stresses in the } \\
\text { rock mass. } \\
\text { - Water. } \\
\text { - Capacity and installation } \\
\text { sequence of support } \\
\text { systems. }\end{array}$ & $\begin{array}{l}\text { Stereonet or analytical } \\
\text { methods are used for the } \\
\text { determination and } \\
\text { visualisation of all } \\
\text { potential wedges in the } \\
\text { rock mass surrounding } \\
\text { the tunnel. Parametric } \\
\text { analysis of critical wedges } \\
\text { using limit equilibrium } \\
\text { (LE) or direct analysis } \\
\text { using distinct element } \\
\text { method (DEM) on the } \\
\text { mode of failure, factor of } \\
\text { safety and support } \\
\text { requirements. }\end{array}$ & $\begin{array}{l}\text { Factor of safety, including } \\
\text { the effects of } \\
\text { reinforcement, should } \\
\text { exceed } 1.5 \text { for sliding and } \\
2.0 \text { for falling wedges and } \\
\text { blocks. Support installation } \\
\text { sequence is critical and } \\
\text { wedges or blocks should } \\
\text { be identified and } \\
\text { supported before they are } \\
\text { fully exposed by } \\
\text { excavation. Displacement } \\
\text { monitoring is of little } \\
\text { value. }\end{array}$ \\
\hline 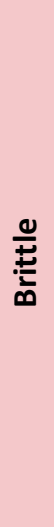 & & $\begin{array}{l}\text { Stress driven instability } \\
\text { leading to spalling or } \\
\text { slabbing of the rock } \\
\text { surrounding the } \\
\text { excavations leading to } \\
\text { eventual tunnel } \\
\text { collapse if rock support } \\
\text { is inadequate. Rock } \\
\text { bursting potential. }\end{array}$ & $\begin{array}{l}\text { - In situ stresses } \\
\text { (magnitude and } \\
\text { orientation) in the rock } \\
\text { surrounding the } \\
\text { excavations. } \\
\text { - Orientation, inclination } \\
\text { and shear strength of } \\
\text { structural features. } \\
\text { - Rock mass spalling } \\
\text { strength. } \\
\text { - Shape and orientation of } \\
\text { the tunnel. } \\
\text { - Capacity and installation } \\
\text { sequence of support } \\
\text { systems. }\end{array}$ & $\begin{array}{l}\text { Empirical design, or stress } \\
\text { analysis using numerical } \\
\text { methods, to determine } \\
\text { the depth failure and } \\
\text { probable displacements. }\end{array}$ & $\begin{array}{l}\text { Support must be capable } \\
\text { of stabilising fractured } \\
\text { rock and accommodate } \\
\text { imposed loads and } \\
\text { displacements. }\end{array}$ \\
\hline 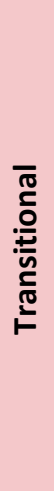 & & $\begin{array}{l}\text { Brittle failure of intact } \\
\text { rock and movement of } \\
\text { blocks or shear failure } \\
\text { of rock mass and } \\
\text { movement of blocks. } \\
\text { Large deformations and } \\
\text { significant yielding } \\
\text { possible where support } \\
\text { is inadequate. }\end{array}$ & $\begin{array}{l}\text { - Orientation, inclination } \\
\text { and shear strength of } \\
\text { structural features. } \\
\text { - Excavation method and } \\
\text { sequence. } \\
\text { - Quality of excavation } \\
\text { drilling and blasting. } \\
\text { - Shape and orientation of } \\
\text { the tunnel. } \\
\text { - In situ stresses. } \\
\text { - Rock mass compressive } \\
\text { strengths. } \\
\text { - Capacity and installation } \\
\text { of support systems. }\end{array}$ & $\begin{array}{l}\text { Complex interaction of } \\
\text { tunnel instability modes } \\
\text { requires numerical } \\
\text { analysis to predict depth } \\
\text { of failure and } \\
\text { displacements. }\end{array}$ & All of the above. \\
\hline
\end{tabular}


Figure 3 Table from Corkum et al. (2011) illustrating four tunnel conditions and associated problems, critical parameters, analysis methods and acceptability or design criteria

\subsubsection{Deficiencies of classification for support design in deep mines}

Most classifications systems (except MRMR; Laubscher 1990) do not take damage and fracturing from sequential loading and unloading into account. For example, in the Q-system, the stress reduction factor (SRF) is determined for a given, virgin stress state and the cumulative effect of mining induced stress changes (increases and/or decreases) are not considered. In reality, however, such stress changes lead (near the excavation) to cumulative damage with related rock mass degradation (as illustrated by Figure 4 in Kaiser (2006); GSI reduction related to fracturing). The consequence is that rock mass strain resulting from mining induced stress changes is typically underestimated and the resulting strain of the support is thus underestimated. Similarly, the interpreted Geological Strength Index (GSI) for the stress fractured rock is much lower near an excavation (in the inner shell experiencing mining induced stress fracturing; see below), than the natural GSI obtained from virgin ground observations. As a consequence, the stand-up time is drastically reduced (Kaiser 2006) and proper retention systems are needed to ensure support integrity. Consequently, standard classification systems should only be used for excavations that do not experience mining induced stress changes.

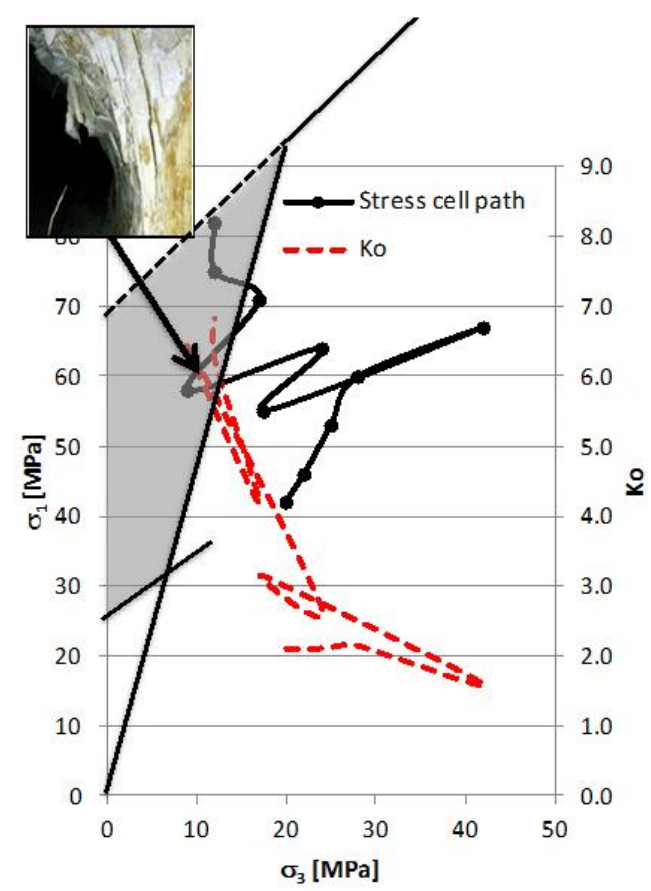

Figure 4 Stress path obtained from field stress measurements at El Teniente Mine (graph produced from data presented by Turichshev et al. (2011)); this figure also presents a typical damage initiation threshold and spalling limit for brittle rocks indicating that the given stress path enters the zone with anticipated stress damage and rock mass spalling (shaded grey)

\section{$2 \quad$ Factors affecting brittle rock failure and sources of deformation}

\subsection{Inner shell - zone of stress fracturing}

Figure 5(a) presents test results from triaxial tests of veined rock (Quartzite; Bewick et al. 2011) illustrating a high degree of strength variability in the inner shell (at about $\sigma_{3}<U C S / 10$ or $<10$ to $15 \mathrm{MPa}$ ) where defects dominate the rock strength. In this inner shell, this rock is particularly sensitive to stress or strain induced rock mass disintegration and, as a consequence, to rock mass bulking (see following). The transition from the inner to the outer shell behaviour can typically be anticipated at $\sigma_{3}<\mathrm{UCS} / 10$. 


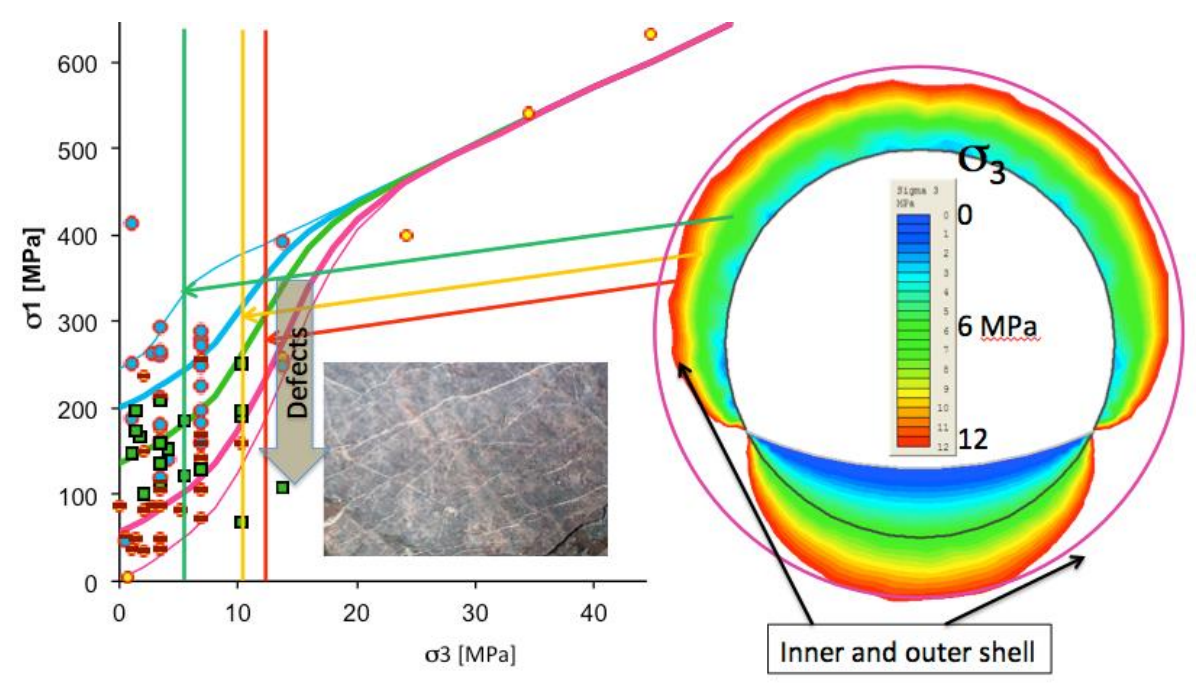

Figure 5 (a) triaxial test data from defected rock (Quartzite) showing failure of intact and flawed samples (Bewick et al. (2011)); and (b) minor principal stress contours around an elastic horse-shoe shaped tunnel; arrows referring to three confining stress levels $(5,10,12$ $\mathrm{MPa}$ )

The degree of rock mass damage in this inner shell varies from crack or fracture initiation to coalescence. In other words, part of the inner shell is stress damaged but still maintains some cohesion, whereas the heavily strained part can be totally disintegrated as shown by Garza-Cruz et al. (2014).

\subsubsection{Depth of failure $\left(d_{f}\right)$}

The depth of failure $\left(\mathrm{d}_{\mathrm{f}}\right)$ can be obtained from the semi-empirical relationship introduced by Kaiser et al. (1996) and refined by many since then (Martin et al. (1999); Diederichs et al. (2010)). The depth of failure, but not the lateral extent of failure, can also be obtained from elastic models using the brittle Hoek-Brown or $m=0$ approach introduced by Martin et al. (1999).

\subsubsection{Rock mass bulking factor}

Since the rock inside the depth of failure is totally disintegrated and in a zone of low confinement, it tends to bulk-up under wall parallel straining, as the rock fragments no longer fit geometrically. As a result, this stress fractured rock moves radially or laterally into the excavation. This bulking imposes non-elastic strains on radial support elements such as bolts and retaining systems such as shotcrete and mesh. In an effort to estimate a semi-empirical measure of bulking, the term bulking factor (BF) was introduced by Kaiser et al. (1996), where BF is defined as the change in length per unit (radial or lateral) length. This bulking factor can be obtained from radial extensometer measurements.

The bulking factor depends on the confining pressure or the radial pressure imposed by the support, the reinforcement effects of the support (which reduces the opening of fractures and prevents the rotation of rock fragments), as well as the strain imposed on the fractured rock (tangential to the excavation wall). Higher support pressures and reinforcement reduce BF and larger wall straining increases BF. Typical bulking factors range from $2-15 \%$ for heavily to lightly supported ground and may reach $30 \%$ or more if unsupported (Kaiser et al. 1996). During tunnel development in virgin ground, the bulking factors are much smaller (typically less than $2 \%$ ) but increase rapidly when mining-induced strains are imposed. As a consequence, bulking factors obtained from early mine developments are not representative for late stage mining when much larger wall strains are imposed. The values quoted above (2-15\%) are only encountered when large strains are imposed, e.g. in highly loaded pillar walls. 


\subsubsection{Ground reaction curve with rock mass bulking}

The ground reaction curve (or Fenner-Pacher curve named after its original developers) describes the interaction of ground deformation (convergence) during tunnel advance and support deformation. An example is presented in Figure 6 for a deep circular tunnel excavated in good ground (GSI $=65$ ).

It is evident from this example of tunnel advance in virgin ground that the bulking deformation, after support installation at $25 \mathrm{~mm}$ wall displacement, already dominates the support deformation (30 of $35 \mathrm{~mm}$ stems from bulking). Any mining induced strain would aggravate this situation.

\subsubsection{Deficiencies of numerical modelling}

Since continuum models cannot properly reproduce the unidirectional bulking process and the related elevated straining of the support, most continuum models tend to underestimate the support loads from stress fracturing. Fortunately, rock reinforcement often reduces the bulking factor such that model predictions match measurements if the reinforcement is effective. However, when large mining induced strains are imposed, and the bulking factor increases rapidly, these models are inadequate to capture the support loads from stress-fractured ground. While discontinuum codes may get the bulking right, most of these codes are deficient in terms of support modelling; most if not all do not capture the reinforcement effect that can reduce the bulking and the variability in strain distributions along the bolts (displacement profile between opening fractures and intact rock blocks).

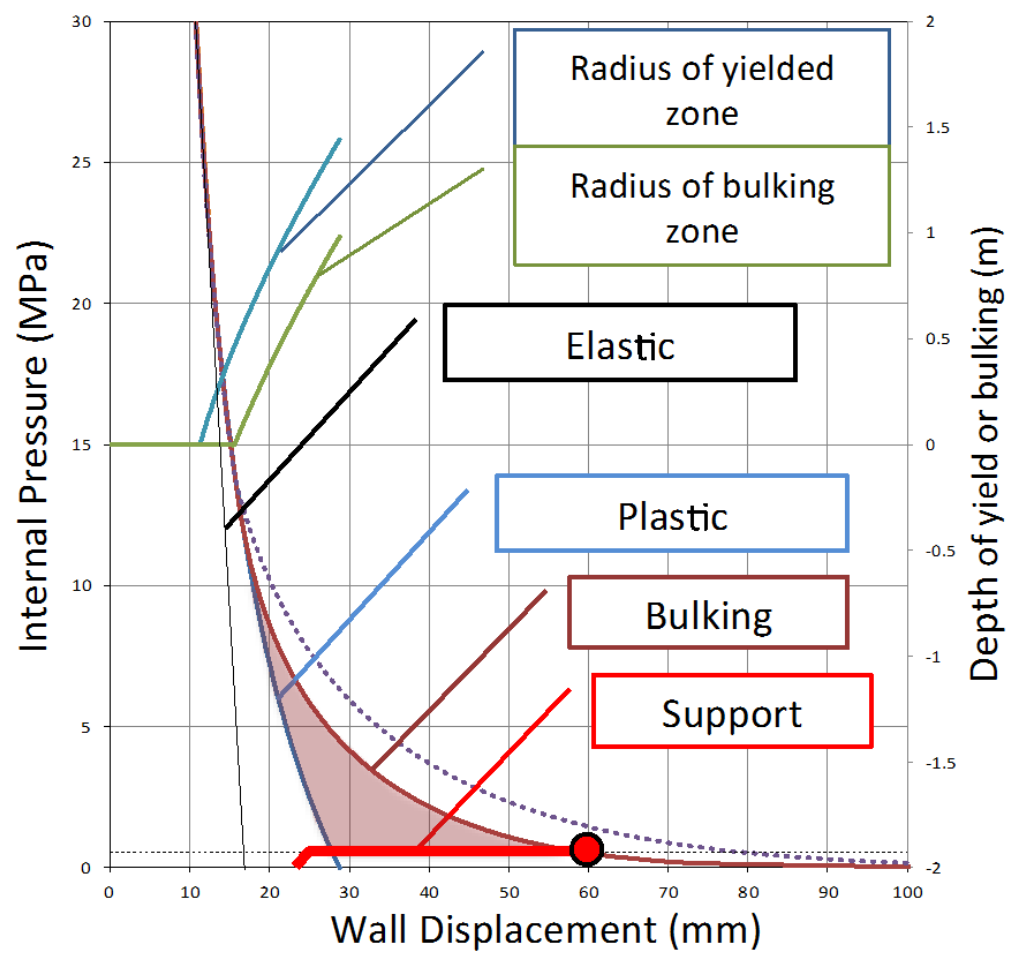

Figure 6 Ground-Reaction-Curve concept expanded for rock mass bulking showing for a given set of engineering parameters: the solutions for elastic, plastic and plastic with bulking ground; the depth of yield and depth of bulking is also show (reaching 1.5 and $1 \mathrm{~m}$ respectively in this case); the yielding support shown provides a relatively high support resistance of $0.5 \mathrm{MPa}$

\subsection{Excavation vulnerability}

Heal et al. (2006) introduce a very important concept of excavation vulnerability potential (EVP) to relate the seismically induced excavation damage to four excavation vulnerability enhancing factors: stress condition, support capacity, excavation span, and influence of geological structure. Kaiser and Cai (2013a, b) supported the need for assessing the EVP for support design, discussed some of the limitations of the 
proposed approach and concluded that there is one often dominant factor that was not considered and needed to added, i.e. the excavation deformation potential (EDP). As the stiffness of a test frame affects the post-peak behaviour of brittle failing rock, the mine stiffness also affects the severity or violence of failure of an excavation in brittle rock.

A high mine stiffness means that the excavation has little deformation potential, i.e., it imposes relatively little tangential strain on a volume of rock failing near the excavation. This is encountered when a single tunnel is advanced in virgin ground. The mine stiffness decreases with increasing extraction ratio (ER) or the EDP increases with increasing ER. An otherwise equivalent tunnel will experience a different deformation potential as mining affects the deformability of the rock mass surrounding the tunnel. This is illustrated schematically in Figure 7 where situation A has a lower EDP than situation B.

As correctly identified by Heal et al. (2006), geological structures also enhance the EVP. In their work, they focused however, on factors that increase the potential for seismically induced falls of ground. Kaiser and Cai (2013a) pointed out that geological structures also enhance the deformation potential as faults intersecting excavations alter the convergence profile. Kaiser and Cai (2013a) illustrated this on an example (Thöny 2013) showing large variations in convergence as a fault zone was approached. The EDP varied by almost one order of magnitude within a few metres along the tunnel. The conclusion that the deformation potential increases as faults are intersected is not new, as it is well know that the burst potential is much larger when mining toward faults than when mining away from faults (Salamon 1993) Geological structures intersecting excavations (similar to changes in excavation geometry) create local changes in EDP. The implications of this for the prediction of strainburst potential are discussed in Section 3.

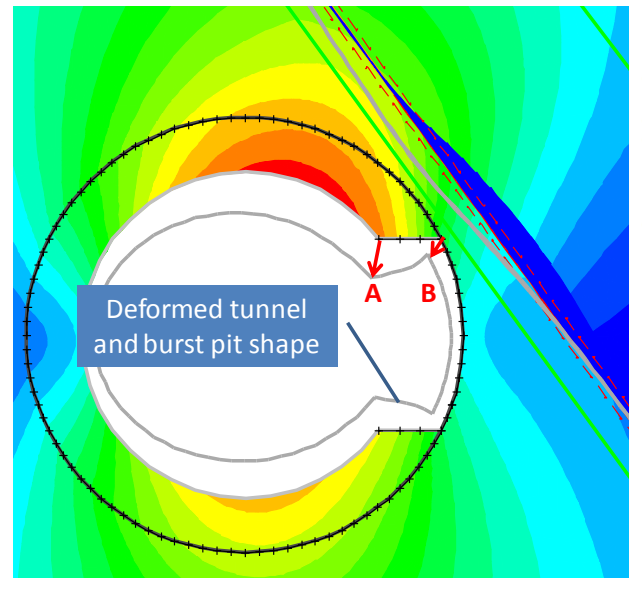

(a)

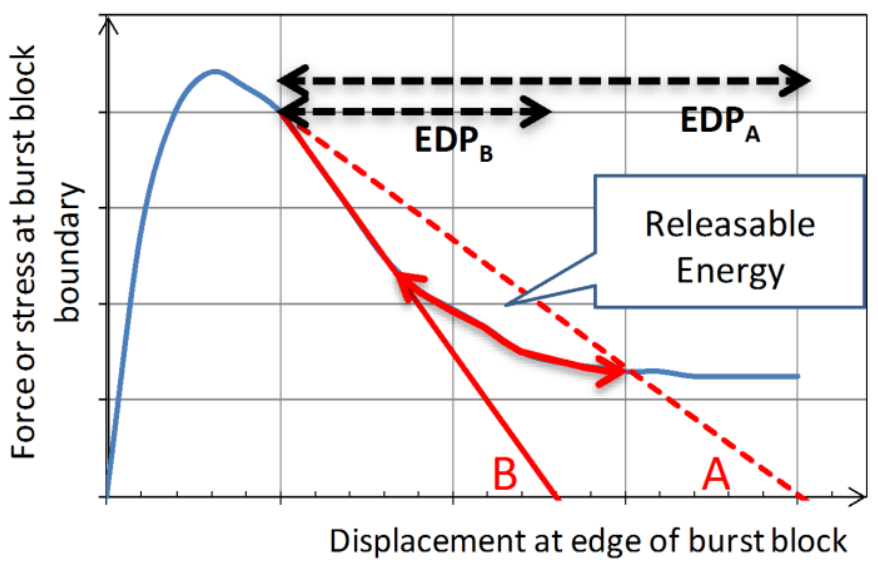

(b)

Figure 7 (a) deformed tunnel shape after removal of a volume of failed rock (called burst pit); (b) rock mass deformation curve showing two excavation deformation potentials $\left(E D P_{A}>E D P_{B}\right)$; full double arrow indicates deformation path of fractured rock that will contribute to rock mass bulking

\section{$3 \quad$ Strainbursting}

Three rockburst types are typically recognised (fault slip, pillar and strainbursts; Kaiser et al. 1996) and since a rockburst is defined as damage to an excavation that occurs in a sudden and violent manner and is associated with a seismic event, all rockbursts cause excavation damage. However, two damage mechanisms are directly related to ground motion from a remote seismic source (seismic shakedown and rock ejection) while the third (strainbursting) may or may not be related to a damage causing seismic event, i.e. rock failure at the excavation produces the seismic source, as illustrated by Figure 8 . 


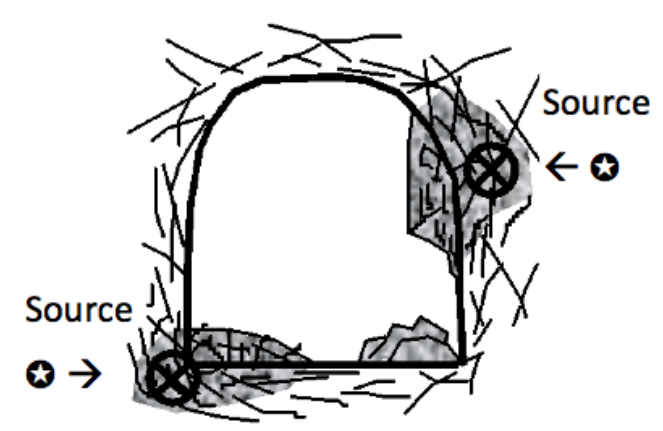

\section{Figure 8 Illustration of strainburst as an excavation damage process. The damage causing events or strainburst related sources (arrows) are collocated}

For shakedown, the engineering design model is based on the assumption that the seismic shaking adds an acceleration that depends on the frequency and amplitude of the incoming wave.

For rock ejection, the design approach assumes that the ground motion is magnified at the excavation causing an ejection velocity $v_{e}=n * p p v$, and that Newton's law applies whereby the ejection energy can be obtained from $E=m * v_{e}^{2} / 2$. In this case, it is implied that all available energy is to be dissipated by the support system, even though some energy is dissipated in other ways, and it follows that the bolt forces of a yielding support system with a fixed allowable, ultimate deformation are proportional to $v_{e}{ }^{2}$.

For strainbursting, the energy stored in the mining system must be considered as the primary driver of failure.

\subsection{Strainbursting - a sudden, violent bulking process}

As Figure 8 shows, strainbursting is a sudden bulking process that can be self-initiated, seismically triggered by a primary seismic event, or dynamically loaded by the dynamic stresses caused by a remote seismic event. Accordingly, three types strainburst damage may be encountered:

- Self-initiated strainburst (or fall of ground):

- Excavation damage due to stress exceeding supported rock capacity with energy release due to relatively low loading system (mine) stiffness relative to the post-peak slope of the failing rock mass.

- Seismically triggered strainburst (or fall of ground):

- Stress wave from a seismic source initiates the failure, i.e. triggers the damage process, but the damage is, as above, not related to the seismic energy at the remote source; it is again related to the loading system stiffness and the energy stored in the system.

- Dynamically loaded strainburst (or fall of ground):

- Stress wave from seismic source causes a dynamic stress increment that triggers the damage process and also deepens the failure zone and thus adds deformation or strain to the failing ground. In this case the damage severity is affected by the mine stiffness and the energy of the primary, remote seismic event.

In these situations, the energy causing damage is primarily related by the local deformation or excavation deformation potential, as illustrated by Figure 7. Before failure, the boundary around a volume of rock that is prone to failure is in equilibrium with the surrounding rock mass. After failure, a new stable equilibrium is reached but the deformed shape differs. Hence, the failing material is exposed to a limited deformation pool as illustrated by Figure 7, e.g. as illustrated by lines $A$ and $B$ and the difference between $E P_{A}$ and $E D P_{B}$ ). In other words, the failing rock is spring loaded with the energy available in the spring (called pre-compression) being a function of the local mine stiffness and the displacement stored $\left(d_{s}\right)$ in the rock mass. It follows that the available energy clearly is not related to a seismic source but to a system that is 
loaded like a spring. Accordingly, the available energy will be proportional to the mine stiffness and a 'pre-compression' displacement $\left(d_{s}\right)$, i.e. the displacement needed to compress the volume of rock with burst potential. From energy balance considerations, it follows that the forces in a yielding support system (again with a fixed allowable, ultimate deformation limit) are proportional to $d_{s}{ }^{2}$ ( $r a t h e r$ than $v_{e}{ }^{2}$ ).

Hence, the damage potential and as a consequence the support design should not be related to the ground motion but rather to the local EDP.

If an excavation fails suddenly (triggered by a seismic event or not; but without energy input from the triggering seismic event) all the damage causing energy stems from energy stored in the mining system, in the rock surrounding the excavation. If an event adds a dynamic stress, the deformation potential is increased and both the stored and dynamical imposed energy input have to be considered. The assumption that the damaging energy stems from the remote seismic event alone is therefore not conservative. As a matter of fact, it can be shown that the stored energy component is often bigger than the dynamic energy component.

In all of the above described strainburst situations, bursting causes damage by a sudden bulking of fractured rock. If well supported, the bulking is minimised by the support and no rock is ejected as all available energy is consumed in rock fracturing (in friction and heat losses) med and by deforming the support system.

As explained by Kaiser and Cai (2013b), in situations where all other factors are equal (e.g. same stress and rock mass strength), locations with higher EDP are more prone to excavation damage by violent rock mass bulking. Hence, otherwise equivalent tunnels become more burst-prone when either the extraction ratio increases or the excavation geometry changes, or when geological structures (dykes or faults) affect the EDP.

\section{$4 \quad$ Support demand in strainbursting ground}

Damage to an excavation during a rockburst can be either related to the ground motions from a remote seismic event or related to the local deformation potential.

\subsection{Ground motion related damage}

When Newton's law of momentum transfer is applicable, the demand for support design can be related to the energy of the seismic source by estimating possible ejection velocities $\left(v_{\mathrm{e}}\right)$. This is typically done by the application of a scaling law to obtain the anticipated ground motion. The ejection velocity is then obtained by multiplying the peak particle velocity (ppv) by a factor ( $n$ ), ranging from 2 to $>10$. Assuming that no energy is lost by breaking the rock or by friction of the supported ground, the energy demand then is obtained by $E=m v_{e}^{2} / 2$. This approach has serious deficiencies in that the variable ( $\left.n * p p v\right)$ is squared and thus the resulting energy values can vary by at least one order of magnitude depending on the assumed $(n)$. Furthermore, because of the drastic assumption of no other energy losses, the result of this approach can be highly variable (function of $\left(\mathrm{v}_{\mathrm{e}}{ }^{2}\right)$, potentially very conservative and thus costly, and often misleading. With yielding support (assuming a constant pull-out force), the resulting bolt forces are thus related to a highly variable $\left(v_{\mathrm{e}}{ }^{2}\right)$.

\subsection{Deformation-controlled damage}

Based on the above-presented factors affecting the strainburst damage through sudden bulking processes, it follows that an effective support system must be designed to survive the sudden, violent bulking process such that the ultimate wall velocity or the ejection velocity $\left(v_{e}\right)$ is zero. While the demand on the support could be defined for loads, displacements or energy, it is the displacement demand that is most relevant for bulking ground. If the displacement capacity is greater than the displacement demand, the excavation will be stable after the strainburst and the ejection velocity is zero. 


\subsubsection{Deformation-based support selection approach}

The displacement demand can, for example, be calculated by multiplying the anticipated depth of failure $\left(d_{f}\right)$, obtained from semi-empirical depth of failure charts, by a representative bulking factor (Kaiser et al. 1996). In dynamically stressed strainbursts, the dynamic deepening effect of the depth of failure needs to be assessed (Kaiser et al. 1996) such that the related bulking increment can be added.

Most importantly, based on the above elaborations, it is necessary to identify EDP-enhancing factors such as geological structures intersecting an excavation. From the case history presented below, it follows that this may be the most important factor for burst location identification.

Furthermore, as indicated above, the ultimate excavation shape after the strainburst is typically stable, which means that the deformation pool available to deform the fractured rock is limited. By analogue to a testing machine with a defined stiffness, it follows that the deformations during failure and thus the bolt deformations in a yielding support system are related to the system or mine stiffness. In other words, the bolt deformations are related to EDP-squared (not the ejection velocity squared). This EDP generally increases with increasing extraction ratio. As a consequence, the anticipated deformation during rock fracturing needs to be estimated for support design and the displacement factor of safety applied (note: it is always advisable to check the load safety or potentially the energy safety as well).

\subsubsection{Deformation control}

The estimated deformation demand is based on an estimate of the depth of failure and the anticipated bulking factor that depends on the support's effectiveness in controlling bulking and the mining-induced straining of the wall rock.

Since rock reinforcement reduces the bulking factor by preventing fractures from opening and propagating, effective reinforcement must be used in strainburst control. However, it must be assumed that these bolts will locally get strained excessively and may fail. Thus, a second line of defence such as yielding bolts or deep anchored debonded cables is needed to ensure support system stability with good connections to a reliable retention system of mesh and shotcrete.

\section{$5 \quad$ Case history - EDP at Jinping II tunnels in China}

Five parallel tunnels were advanced, two initially by tunnel boring machine and the others by drilling and blasting. Hundreds of strainbursts, unfortunately some fatal, were encountered during the advance of these tunnels. A geological cross-section together with a local plan view showing the locations of microseismicity and burst is presented in Figure 9.

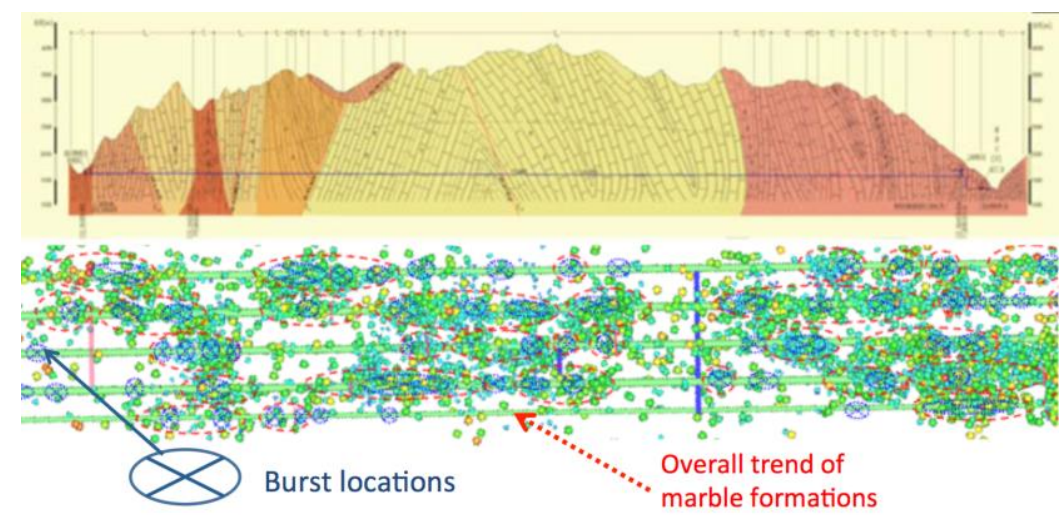

Figure 9 Top: geological section showing typical overburden depth of $>2,000 \mathrm{~m}$ and mostly marble formation in the centre portion of the tunnel; Bottom: plan view of area experiencing over 60 rockbursts (red to green: microseismicity; blue ellipses with cross: rockburst location; red dashed ellipses: location of bursting potential identified from 


\section{microseismic data; red dotted arrow: general direction of marble structure/bedding)} Figure courtesy Feng ( personal communication, 2011)

The causes for bursting in these tunnels have been studied by many from a researcher, designer and contractor perspective. Based on the discussion presented above, it is suggested here that variations in EDP might assist in understanding apparently random bursting patterns.

First, the marginal tunnels are in a stiffer mining environment because of the stress shedding effect of the abutments on either side and thus should have a lower EDP than the central tunnels. Qualitatively this seems to be reflected in the less frequent and less severe burst damage to these tunnels. Furthermore, the tunnel at the bottom of Figure 9 is smaller in size, which further reduced its EDP.

Second, it is hypothesised that an increase in EDP, resulting from geological structures, might be one of the most dominant factors in dictating the location of strainbursting at Jinping II. The dominant structures of the marble are typically inclined at about $30-35^{\circ}$ to the tunnel axis as (Figure 9). If this was the case, then larger seismic events should be aligned with the formation structure and locations of bursting should be aligned in this direction too. This is explored in the following figures.

In Figure 10, the larger events have been connected in sequence for the cluster on the left. Since the tunnels were not advanced at the same rate, time sequence is of no value in identifying EDP related events. 'In sequence' here means events that are roughly aligned in the direction of similar EDP, i.e. parallel to the marble formation. While there is clearly an interpretation bias to this approach, there is no other way (other than detailed modelling) to identify EDP related events. It is interesting to note that the boundaries of this sequence line are roughly parallel to the overall formation orientation. On either side, there is less activity and fewer rockbursts. Fourteen bursts are inside the zone and only about four to five each are found on either side in a comparable volume of rock. This suggests that the bursting pattern is not random but aligned with a zone of geologically controlled, elevated EDP.

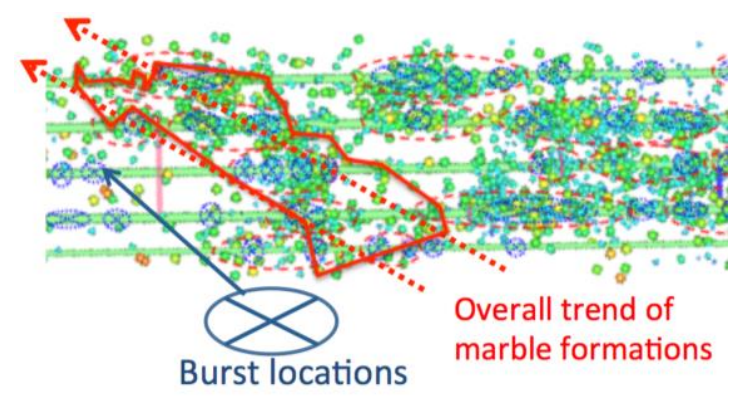

Figure 10 Close-up view with the full line sequentially connecting the largest seismic events

In Figure 11, two-sided arrows are drawn to connect two or more rockburst locations roughly in the direction of the overall formation. Again there is a bias introduced as other connections could be established. However, the systematic pattern of aligned burst is striking. This again suggests that the bursting pattern is not random but aligned with zones of higher EDP. If each burst encountered in a tunnel was used to forward or backward project to the remaining tunnels, the locations of almost all bursts could have been predicted. 


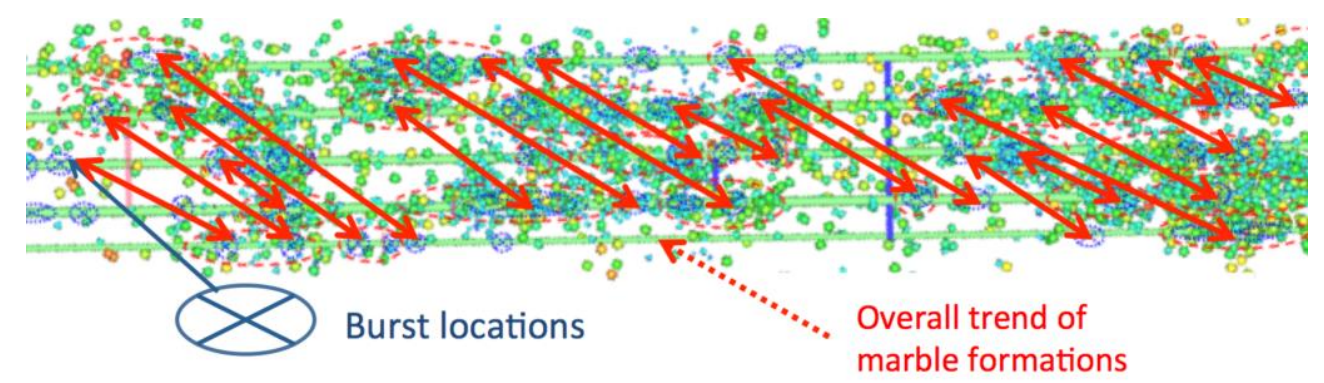

Figure 11 Plan view with two-sided arrows connecting two or more rockburst locations in the direction of the overall trend of the marble formation

There is no doubt that the adopted approach to data interpretation is based on the preconceived notion that the EDP is elevated along geological structures and that, therefore, locations aligned with such structures should be equally prone to bursting. However, it is entirely plausible and consistent with strainbursting at other projects, that burst locations should be aligned with zones of elevated EDP. Clearly there are other factors affecting the strainburst potential such as the rock's brittleness, the strength and the stress ratio, etc., but this example suggests that more attention has to be paid to the EDP.

While much further work is needed to conclusively prove the underlying hypothesis, it is suggested that strainburst damage locations should be used to identify other potential strainburst location based on equivalent or higher EDP. It is also suggested that the EDP must be added to the EVP-index proposed by Heal et al. (2006) before it can be systematically used to assess rockburst damage.

\section{Conclusion}

For excavations in brittle failing rock under high stress, mining induced stress changes, the bulking characteristics of the rock mass in the inner shell, and the excavation damage potential EDP must be assessed for support selection. For self-initiated and seismically triggered strainbursts, the damage process is one of sudden bulking and the support has to survive the related sudden volume increase and related radial straining. Hence, the primary design criterion is the factor of safety based on displacement. While there is an incremental deepening of the failure zone during dynamically loaded strainburst, the ultimate damage zone is limited and the support has to survive the additional deformations from the dynamic deepening of the failure zone. Thus, a design satisfying a factor of safety based on displacement is also applicable for dynamically loaded strainbursts. Energy based design, using only the recorded energy of the co-located seismic event is questionable and thus not recommended. The concept of EDP was introduced to identify potential strainburst location. While not conclusively proven, it is suggested that the EDP, as a means of assessing deformation potential, could help identify strainburst-prone locations.

\section{Acknowledgement}

The author thanks $\mathrm{Dr}$ Feng for providing a case example for the excavation damage potential interpretation. This work was in part funded by Natural Sciences and Engineering Research Council of Canada (NSERC) and benefited from observations at deep mines in Canada and around the world. The in-kind contributions of many mines owned by Glenore, Newcrest, Rio Tinto and Vale are gratefully acknowledged.

\section{References}

Bewick, RP, Kaiser, PK \& Valley, B 2011, 'Interpretation of triaxial testing data for estimation of the Hoek-Brown strength parameter $\mathrm{mi}^{\prime}$, in GS Esterhuizen, AN Tutuncu \& AT lannacchione (eds), Proceedings of the 45th US Rock Mechanics/Geomechanics Symposium, American Rock Mechanics Association, Alexandria.

Corkum, A, Lorig, L, DeGagné, D \& Jakubec, J 2011, Guidelines for Mine Tunnel Support Design Revision 1, report to Mine Tunnel Support project sponsors, Itasca Consulting Group, Inc., SRK Consulting Ltd. and BGC Engineering Inc.; based on: Hoek, E 2007, Practical Rock Engineering, http://www.rocscience.com/hoek/pdf/Practical_Rock_Engineering.pdf, and Diederichs, 
MS 2007, 2003 'Mechanistic Interpretation and Practical Application of Damage and Spalling Prediction Criteria for Deep Tunneling', Canadian Geotechnical Journal, vol. 44, pp. 1087-1116.

Diederichs, MS, Carter, T \& Martin, D 2010, 'Practical rock spall prediction in tunnels', Proceedings of the 2010 World Tunnelling Congress, Tunnelling Association of Canada, Richmond, paper no. 517.

Garza-Cruz, TV, Pierce, M \& Kaiser, PK 2014, 'Use of 3DEC to study spalling and deformation associated with tunnelling at depth', in M Hudyma \& Y Potvin (eds), Proceedings of the Seventh International Conference on Deep and High Stress Mining, Australian Centre for Geomechanics, Perth, pp. 421-434.

Heal, D, Potvin, Y \& Hudyma, M 2006, 'Evaluating rockburst damage potential in underground mining', in DP Yale, SC Holtz, C Breeds \& U Ozbay (eds), Proceedings of the 41st US Symposium on Rock Mechanics, American Rock Mechanics Association, Alexandria.

Kaiser, PK \& Cai, M 2013a, 'Critical review of design principles for rock support in burst-prone ground - time to rethink!', in Y Potvin \& B Brady (eds), Proceedings of the Seventh International Symposium on Ground Support in Mining and Underground Construction, Australian Centre for Geomechanics, Perth, pp. 3-38.

Kaiser, PK \& Cai, M 2013b, 'Rockburst damage mechanisms and support design principles', in A Malovichko \& D Malovichko (eds), Proceedings of the 8th International Symposium on Rockbursts and Seismicity in Mines: RaSiM8, Geophysical Survey of Russian Academy of Sciences, Obninsk, Mining Institute of Ural Branch of Russian Academy of Sciences, Perm, pp. 349-370.

Kaiser, PK, Diederichs, MS, Martin, CD, Sharp, J \& Steiner, W, 2000, 'Underground works in hard rock tunneling and mining', Proceedings of the Proceedings of the International Conference on Geotechnical and Geological Engineering: GeoEng2000, vol. 1, Technomic Publishing Co. Inc., Lancaster, pp. 841-926.

Kaiser, PK, McCreath, DR \& Tannant, DD 1996, Rockburst Support Handbook, vol. 2, original version in Canadian Rockburst Research Program 1990-95, Canadian Mining Industry Research Organization, Sudbury.

Kaiser, PK 2006, 'Rock mechanics consideration for construction of deep tunnel in brittle ground', Proceedings of the 4th Asian Rock Mechanics Symposium, World Scientific Publishing, Singapore, on CD-ROM.

Laubscher, DH 1990, 'A geomechanics classification system for the rating of rock mass in mine design', Journal of the South African Institute of Mining and Metallurgy, vol. 90, no. 10, pp. 257-273.

Martin, CD, Kaiser, PK \& McCreath, DR 1999, 'Hoek-Brown parameters for predicting the depth of brittle failure around tunnels', Canadian Geotechnical Journal, vol. 36, no. 1, pp. 136-151.

Salamon, MDG 1993, Some applications of geomechanical modelling in rockburst and related research, Rockbursts and Seismicity in Mines, in RP Young (ed.), Proceedings of the $3^{\text {rd }}$ International Symposium on Rockbursts and Seismicity in Mines, A.A. Balkema, Rotterdam, pp. 297-309.

Thöny, R 2014, 'Geomechanical analyses of excavation-induced rock mass behaviour of faulted Opalinus Clay at the Mont Terri Underground Research Laboratory (Switzerland)', PhD thesis, no. 21415, Eidgenössische Technische Hochschule Zürich, Zürich, Switzerland.

Turichshev, A, Hadjigeorgiou, J, Brzovic, A, Reyes-Montes, J \& Nasseri, MHB 2011, 'Behaviour of veined rock under triaxial compression', Proceedings of the 6th International Conference \& Exhibition on Mass Mining: MassMin2012, Canadian Institute of Mining, Metallurgy and Petroleum, Westmount, on CD-ROM.

Yong, S, PK, Kaiser \& S, Löw 2010, 'Influence of tectonic shears on excavation-induced fracturing', International Journal of Rock Mechanics and Mining Sciences, vol. 47, no. 6, pp. 894-907. 